Luiz Fernando Portugal Fuchs ${ }^{1}$

Camila RenNó Guimarães ${ }^{2}$

Carla Cristina Maganhin ${ }^{3}$

Ricardo Santos SimÕes ${ }^{4}$

Maria Candida Pinheiro Baracat ${ }^{5}$

José MARIA SOARES JÚNIOR ${ }^{6}$

EDMUnd ChadA BARACAT ${ }^{7}$

Artigo original

Palavras-chave

Glândula pineal/cirurgia

Melatonina/uso terapêutico Melatonina/administração \& dosagem Glândulas supra-renais

Apoptose

Imunoistoquímica

Ratos

Keywords

Pineal gland/surgery

Melatonin/therapeutic use

Melatonin/administration \& dosage

Adrenal glands

Apoptosis

Immunohistochemistry

Rats

\section{Ação da melatonina sobre a apoptose e fator de crescimento endotelial vascular no córtex da adrenal de ratas pinealectomizadas}

\author{
Melatonin action in apoptosis and vascular endothelial growth factor \\ in adrenal cortex of pinealectomized female rats
}

\section{Resumo}

OBJETIVO: avaliar os efeitos da melatonina na apoptose e atividade celular no córtex da adrenal de ratas pinealectomizadas. MÉTODOS: foram utilizadas 40 ratas adultas, divididas randomicamente em 4 grupos com 10 animais cada: GContsem intervenção cirúrgica e com ministração do veículo; GSham - sem retirar a pineal com ministração do veículo; GExpV - pinealectomizado e tratado com veículo; GExpM - pinealectomizado e tratado com melatonina (10 $\mathrm{\mu g} / \mathrm{animal}$, por dia) durante a noite. Após 60 dias de tratamento, todos os animais foram submetidos à eutanásia, as adrenais retiradas, fixadas em formol a 10\% e processadas para inclusão em parafina. Nos cortes histológicos com 5 um de espessura, foram realizados métodos imunoistoquímicos para detecção da apoptose (Caspase-3-clivada) e da atividade celular (fator de crescimento endotelial vascular, VEGF-A). Para avaliar a percentagem de apoptose foram contadas as células reativas em 1.000 células de cada zona da região cortical da adrenal em cada animal; já o VEGF-A foi expresso em escores. Os dados quantitativos foram analisados pela análise de variância (ANOVA) e pelo teste de comparações múltiplas de

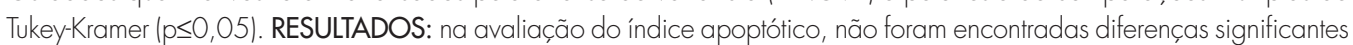

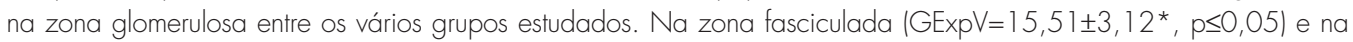
reticulada (GExpV=8, $11 \pm 1,90 *$, $p \leq 0,05)$ houve redução no índice apoptótico no grupo GExpV em relação aos demais grupos de estudo. Na reatividade ao VEGF-A, houve maior positividade, indicando maior atividade celular na zona na fasciculada do GExpV em relação aos outros grupos. CONCLUSÕES: a melatonina ałua na região cortical da adrenal, em especial nas zonas fasciculada e reticulada, que estão relacionadas com a produção de esteroides sexuais.

\section{Abstract}

PURPOSE: to evaluate the reactivity of VEGF-A and cleaved caspase-3 in the adrenal gland cortex of female pinealectomized rats treated with melatonin. METHODS: forty adult female rats were divided into 4 groups (G) of 10 animals: $G$ l - no surgical intervention, with vehicle administration; GII - sham pinealectomized with vehicle administration; GIII - pinealectomized with vehicle administration; GIV - pinealectomized with melatonin administration (10 $\mu \mathrm{g} /$ animal) during the night. After 60 days of treatment, all animals were anesthetized, and the adrenal glands were removed and fixed in 10\% formaldehyde (phosphate buffered) for histological processing and paraffin embedding. Sections (5 $\mu \mathrm{m}$ thick) were collected on silanized slides and submitted to imunnohistochemical methods for the detection of cleaved caspase-3 (apoptosis) and of vascular endothelial growth factor (VEGF-A) in the adrenal cortex. The data obtained were submitted to analysis of variance (ANOVA) complemented by the Tukey-Kramer test $(p \leq 0.05)$. RESULTS: reactivity to cleaved Caspase-3 was noted in the zona glomerulosa of the adrenal glands in all studied groups. There were no significant differences in the zona glomerulosa; however, the zona fasciculata $(15.51 \pm 3.12 *, p \leq 0.05)$ and the zona reticularis $(8.11 \pm 1.90 *, p \leq 0.05)$ presented the smallest percentage of apoptosis in the pinealectomized group (GIII). The reactivity to the VEGF-A was stronger in the zona glomerulosa and weaker in the zona reticularis in all groups. We found a stronger VEGF-A reactivity in the zona fasciculata in the pinealectomized group (GIII). CONCLUSIONS: the pineal gland affects the arrangement of the zona glomerulosa and reticularis of the adrenal glands, which are related to the production of sex hormones.
Correspondência:

José Maria Soares Junior Rua Sena Madureira, 1245 apt. 11 - Vila Clementino (EP: 04021-051 - São Paulo (SP), Brasil E-mail: ssoares415@hotmail.com

Recebido

$13 / 5 / 10$

Aceito com modificaçōes $18 / 8 / 10$
Departamento de Ginecologia da Universidade Federal de São Paulo - UNIFESP - São Paulo (SP), Brasil.

'Pós-Graduando (Mestrado) em Ciências da Saúde, Departamento de Ginecologia da Universidade Federal de São Paulo - UNIFESP - São Paulo (SP), Brasil.

2Aluna de Iniciação Científica (PIBIC) do Departamento de Ginecologia da Universidade Federal de São Paulo - UNIFESP - São Paulo (SP), Brasil.

${ }^{3}$ Mestre em Ciências da Saúde, Disciplina de Histologia e Biologia Estrutural da Universidade Federal de São Paulo - UNIFESP - São Paulo (SP), Brasil.

${ }^{4}$ Médico Assistente do Hospital Universitário da Universidade de São Paulo - USP; Pós-Graduando (Mestrado) do Departamento de Obstetrícia e Ginecologia do Hospital das Clínicas da Faculdade de Medicina da Universidade de São Paulo - USP - São Paulo (SP), Brasil.

${ }^{5}$ Aluna de Iniciação Científica (PIB|C) do Departamento de Morfologia e Genética da Universidade Federal de São Paulo - UNIFESP - São Paulo (SP), Brasil.

oProfessor Livre-Docente da Disciplina de Endocrinologia Ginecológica da Universidade Federal de São Paulo - UNIFESP - São Paulo (SP), Brasil.

7Professor Titular e Chefe da Disciplina de Ginecologia do Hospital das Clínicas da Faculdade de Medicina da Universidade de São Paulo - USP - São Paulo (SP), Brasil.

Conflito de interesse: não há. 


\section{Introdução}

As suprerrenais são glândulas endócrinas constituídas por duas regiões: a medular, produtora de adrenalina e noradrenalina, e a cortical, que produz corticosteroides e andrógenos (deidroepiandosterone [DHEA] e androstenediona) ${ }^{1}$, cuja secreção está na dependência de hormônios e fatores teciduais. A região cortical da adrenal sintetiza inúmeros hormônios a partir do colesterol; assim, a aldosterona é produzida principalmente pelas células da zona glomerulosa, o cortisol/corticosterona é produzido principalmente pelas células da zona fasciculada e DHEA e androstenediona sintetizada pelas células da zona reticular $^{1}$. Assim, o hormônio adrenocorticotrófico (ACTH) estimula o cortisol/corticosterona, a angiotensina II (AII) e o potássio regulam a síntese da aldosterona. Deve ser mencionado que o ACTH e os hormônios luteinizante (LH) e foliculoestimulante (FSH) induzem a esteroidogênese na adrenal e nas gônadas pela ligação aos seus receptores acoplados à proteína $G$, levando à ativação da guanilato ciclase, que gera AMPc e ativa cAMP-dependente da proteína quinase $(\mathrm{PKA})^{2}$.

Jung et al. ${ }^{3}$ avaliaram indivíduos expostos a 6,7 horas de luz por dia (cerca de 10.000 Lux; equivalente à intensidade de luz ambiente logo após o nascer do sol ou um pouco antes do pôr-do-sol) e notaram redução significativa dos níveis do cortisol plasmático, referindo haver um mecanismo pelo qual a informação luminosa influencia profundamente as glândulas suprarrenais. Acreditam haver vias neurais e endócrinas do núcleo supraquiasmático do hipotálamo com outras áreas corticais relacionadas à luz e às glândulas suprarrenais.

Em mamíferos, a produção da melatonina pela glândula pineal é controlada principalmente pelo núcleo supraquiasmático do hipotálamo ${ }^{4}$. Nesse sentido, a pineal influencia as gônadas e a ciclicidade estral em ratas, além de atuar como moduladora da reprodução em mamíferos ${ }^{5}$. Através dos níveis séricos de melatonina, que variam conforme a fase do ciclo estral, pode-se avaliar a sua atividade, que se intensifica durante a noite, durante a qual ocorre um pico deste hormônio ${ }^{6,7}$.

A melatonina, também conhecida como $\mathrm{N}$-acetil-5metoxitriptamina, é o principal hormônio da pineal. Tem uma coloração amarelo claro, com alta lipossolubilidade, sendo transportada no plasma ligada a proteínas, especialmente a albumina; tem vida média de 30 a 60 minutos. Seu ápice ocorre por volta da meia-noite, havendo queda durante o dia ${ }^{7,8}$.

Estudos mostram que ratas expostas a estímulo luminoso contínuo apresentam queda na quantidade da melatonina produzida, levando a alterações no ciclo estral que prolongam a fase de estro 9 . No entanto, a ministração exógena de melatonina a ratas pinealectomizadas ou submetidas à iluminação contínua regularizou o ciclo ${ }^{8}$. Além disso, observou-se queda no nível do hormônio folículo-estimulante (FSH) após a pinealectomia, levando a um comprometimento da função folicular e da produção hormonal ovariana ${ }^{10}$.

Com relação ao efeito da melatonina na adrenal, os trabalhos são escassos. Alguns estudos referem hipertrofia da cortical da adrenal em ratas submetidas à iluminação contínua ${ }^{11}$. Este estudo se propôs a avaliar os efeitos da melatonina na apoptose e no fator de crescimento endotelial vascular do córtex da adrenal de ratas pinealectomizadas.

\section{Métodos}

Foram utilizadas ratas (Rattus norvegicus albinus) adultas, virgens, pesando aproximadamente $250 \mathrm{~g}$, fornecidas pelo Centro de Desenvolvimento de Modelos de Experimentação (CEDEME) da Escola Paulista de Medicina, Universidade Federal de São Paulo (UNIFESP-EPM). Este estudo foi aprovado pelo Comitê de Ética em Pesquisa da UNIFESP/ EPM (parecer $n^{\circ} 069$ 3/07), seguindo as diretrizes do Conselho Canadense para os Cuidados dos animais ${ }^{12}$.

Os animais foram mantidos em gaiolas plásticas, no Biotério da Disciplina de Histologia, com temperatura ambiente controlada a $22^{\circ} \mathrm{C}$ e iluminação artificial obtida com lâmpadas fluorescentes (modelo luz do dia de 40 Watts), com fotoperíodo claro de 10 horas (8:00 às 18:00) e 14 horas escuro, com alimentação e água ad libitum.

Após sete dias, animais com ciclos estrais regulares, ou seja, que apresentaram atividade ovariana regular, foram incluídas no estudo. Assim, 40 ratas foram distribuídas aleatoriamente em quatro grupos: Grupo Controle (GCont) - animais sem intervenção cirúrgica tratados com veículo; Grupo Sham (GSham) - animais falsamente pinealectomizados tratados com veículo; Grupo experimental (GExpV) - animais pinealectomizados tratados com veículo; Grupo experimental (GExpM) - animais pinealectomizados com reposição de melatonina $(10 \mu \mathrm{g} /$ animal) durante a noite ${ }^{13,14}$.

A melatonina foi reposta durante 60 dias consecutivos, ministrada na água $(0,4 \mu \mathrm{g} / \mathrm{mL})$ em frascos âmbar cobertos com papel alumínio, das 18:00 às 8:00 horas. O início da reposição melatonina ocorreu 21 dias após a realização do ato cirúrgico. A melatonina foi preparada diariamente, dissolvendo-se $400 \mathrm{mg}$ de melatonina cristalina (Sigma Chemical Company, St Louis, MO, USA) em $1 \mathrm{~mL}$ de etanol e esta solução diluída em $1 \mathrm{~L}$ de água filtrada.

\section{Pinealectomia}

A pinealectomia foi realizada segundo o método preconizado por Maganhin et al. ${ }^{15}$, ou seja, os animais foram inicialmente anestesiados com cloridrato de xilazina (20 
$\mathrm{mg} / \mathrm{kg})\left(\right.$ Rompun $\left.^{\circledR}\right)$ e cloridrato de quetamina $(10 \mathrm{mg} / \mathrm{kg})$ $\left(\operatorname{Ketalar}^{\circledR}\right)$, via intraperitoneal. Sob efeito do anestésico, realizou-se a tricotomia da região dorsal do crânio, e os animais foram então posicionados em um aparelho estereotáxico com duas torres (Dual Manipulator Stereotaxic, marca Stoelting). Em seguida, foi realizada uma incisão na linha médio-dorsal do crânio, compreendendo desde a região interauricular até a região interorbitária. As abas de pele foram rebatidas e assim mantidas; a fáscia subjacente e o periósteo raspado de modo a expor a calota craniana. Com um micromotor de baixa rotação (peça de mão) e uma broca esférica $\mathrm{n}^{0} 5$, retirou-se um fragmento circular da calota craniana de aproximadamente $4 \mathrm{~mm}$ de diâmetro, tendo como ponto central de referência o lambda. Esse fragmento foi colocado em solução de cloreto de sódio a $0,9 \%$.

Após a retirada do fragmento da calota craniana, foi possível ver a junção do seio venoso sagital superior e transverso (em forma de Y). Com dois fios de nylon (3-0 Prolene) passados delicadamente por baixo do seio sagital, um próximo à confluência dos seios e outro mais afastado deste ponto, de modo que fossem tracionados, obteve-se a ligadura do seio venoso.

Sob lupa estereoscópica, realizou-se uma incisão entre os dois nós e, em seguida, o nó próximo à confluência foi afastado para visibilização e retirada da glândula pineal por intermédio de pinça de microcirurgia (Roca Inox $\left.{ }^{\circledR}\right)$. Em seguida, o fragmento da calota craniana foi recolocado em seu lugar e as camadas cirúrgicas, suturadas.

A glândula pineal, depois de retirada, foi fixada em formaldeído a $10 \%$ (tampão fosfato) e processada para inclusão histológica em parafina para confirmação à microscopia de luz.

Para eliminar falsos resultados devido ao ato cirúrgico, o mesmo procedimento foi realizado nos animais do grupo GSham, mas sem a retirada da glândula pineal.

\section{Retirada das adrenais}

Vinte dias antes da eutanásia, reiniciou-se a coleta dos esfregaços vaginais até o término do experimento. Ao $60^{\circ}$ dia de tratamento, os animais que estivessem na fase de proestro, fase esta que possui elevada produção de esteroides ovarianos, foram submetidos à eutanásia. Animais que não estivessem nesta fase continuaram a receber a dosagem de melatonina até atingirem o proestro.

Uma vez em proestro, os animais foram anestesiados intraperitonealmente com $15 \mathrm{mg} / \mathrm{kg}$ de xilazina (Rompun) associados a $30 \mathrm{mg} / \mathrm{kg}$ de ketamina (Ketalar), e colocados em posição dorsal, sendo realizada a tricotomia na região. Foi realizada uma incisão abdominal longitudinal na linha média. Após o afastamento dos órgãos (alças intestinais, rins etc.), as adrenais foram localizadas uma em cada lado da aorta abdominal, que foram mergulhadas em formol a
10\% (tampão fosfato $10 \mathrm{mM}, \mathrm{pH} 7,4$ ), e processadas para inclusão histológica em parafina. O preparo e o estudo histológico foram realizados na Disciplina de Histologia e Biologia Estrutural do Departamento de Morfologia e Genética da UNIFESP-EPM.

\section{Avaliação imunoistoquímica}

Para avaliar a expressão do fator de crescimento vascular endotelial VEGF-A, foi utilizado o anticorpo VEGF-A (Dako, Denmark) na diluição 1:30, usando como controle externo uma amostra de tumor de mama positivo para a expressão do VEGF. Para avaliar a expressão da caspase-3 -clivada foi utilizado anticorpo policlonal de rato (Sigma Chemical Corporation, P-7886, Louis MO) na diluição de 1:40, usando como controle externo positivo tecido normal de fígado.

Para tanto, cortes de parafina foram realizados na espessura de $5 \mu \mathrm{m}$ e dispostos em lâminas previamente tratadas com o aderente silano. Em seguida, foi feita desparafinização em xilol e re-hidratação em álcool e água. Para realizar o bloqueio da peroxidase endógena, os cortes foram lavados em água corrente e destilada e incubados em PBS por três vezes durante cinco minutos. A recuperação antigênica foi realizada com tampão citrato $(\mathrm{pH}=6)$ em forno de micro-ondas por 20 minutos, a $90^{\circ} \mathrm{C}$, com descanso das lâminas por mais 20 minutos dentro do forno. Retiradas do forno, as lâminas foram deixadas por 15 minutos em temperatura ambiente, lavadas novamente em água corrente e destilada, e incubadas em PBS. Após aplicação de peróxido de hidrogênio (5\%), foram outra vez lavadas e incubadas em PBS. Os cortes foram circulados com caneta Dako Pen (Dako Lab. Inc. ${ }^{\circledR}$, New York, NY, USA) e adicionou-se o anticorpo primário, deixando em câmara úmida (EasyPath ${ }^{\circledR}$, Erviegas) durante a noite, na geladeira. As lâminas foram retiradas da geladeira, e lavadas com água destilada, e o anticorpo secundário LSAB foi adicionado (avidina biotina, DakoCytomation ${ }^{\mathrm{TM}}$ ) e colocado em câmara úmida por 30 minutos. Após incubação no PBS, repetiu-se o procedimento, adicionando o LSAB (estreptavidina peroxidase, DakoCytomation ${ }^{\mathrm{TM}}$ ). A reação foi revelada com substrato cromogênico diaminobenzidina (DAB, DakoCytomation ${ }^{\mathrm{TM}}$ ) até os cortes ficarem escuros ( \pm 30 segundos), sendo contracorados com hematoxilina por 20 a 30 segundos. Após lavagem em água corrente e aplicação de amônia a 2\%, as lâminas foram novamente lavadas em água corrente, álcool 100\% e xilol para serem montadas e observadas em microscópio de luz.

As análises quantitativa e semiquantitativa foram realizadas no Serviço de Histologia da UNIFESP por histologista experiente. Para tanto, as lâminas foram avaliados cegamente pelo mesmo investigador. As imagens 
foram capturadas através de uma câmera de alta resolução (AxioCam-MCR da Carl Zeiss), microscópio de luz (AxioLab, Carl Zeiss) com objetiva de 40X, e transmitida a computador com software AxionVision Rel 4.2 (Carl Zeiss). Para a avaliação da caspase-3-clivada e do VEGF-A, foram obtidas 5 imagens de cada zona de cada animal, perfazendo um total de 50 imagens por zona em cada grupo e para cada reação.

A imunoistoquímica da expressão da caspase-3-clivada foi revelada pela presença de áreas marrons no citoplasma das células. Visualizando as imagens na tela do computador, foram contadas as células marcadas (apoptóticas) e não-marcadas (não-apoptóticas), em cada zona do córtex da adrenal, perfazendo um total de 1.000 células por animal. Ao final, foi calculada a percentagem de células em apoptose em cada zona da adrenal em cada animal (avaliação quantitativa).

Para análise semiquantitativa, a marcação do VEGF-A foi graduada de acordo com a intensidade da coloração acastanhada no citoplasma das células presentes nas diversas zonas da adrenal, usando os seguintes escores: para ausência de coloração; +para coloração fraca; ++ para coloração média e +++ para coloração forte.

Foi utilizado o teste de análise de variância (ANOVA), acompanhado do teste de comparações múltiplas de Tukey-Kramer, para a análise do índice de apoptose. Fixou-se em 5\% (p<0,05) o nível para rejeição da hipótese de nulidade, assinalando-se com asterisco os valores significantes.

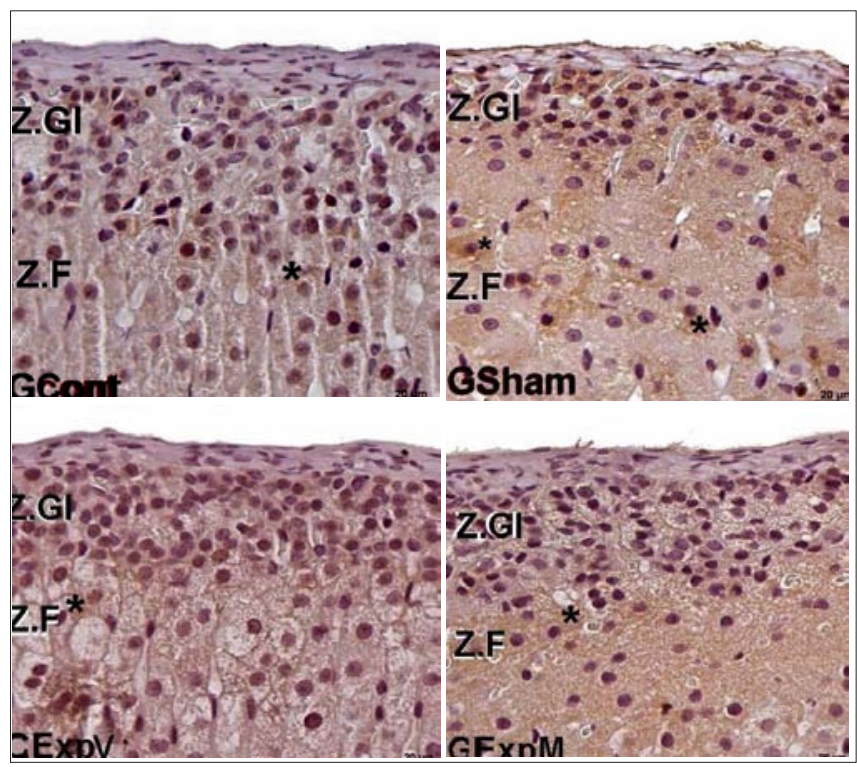

Figura 1 - Fotomicrografias das zonas glomerulosa (Z.Gl) e fasciculada (Z.F) da região cortical das adrenais de ratas pertencentes aos vários grupos de estudo. Notar no citoplasma de algumas células, áreas com coloração marrom indicando reatividade à caspase (asterisco). Grupo Controle (GCont), Grupo Sham (GSham), Grupo pinealectomizado tratado com veículo (GExpV) e Grupo pinealectomizado tratado com melatonina (GExpM). Imunoistoquímica para a caspase-3-clivada. 400X.

\section{Resultados}

À macroscopia, foi observado que as adrenais de todos os animais pinealectomizados e tratados com veículo (GExpV) tinham tamanho maior em relação aos demais grupos. Notamos, ainda, em todas as zonas do córtex das adrenais nos diversos grupos, a presença de células contendo áreas marrons no citoplasma, indicando atividade apoptótica (Figura 1 e 2) ou atividade celular (Figura 3 e 4). Os dados referentes à análise quantitativa da apoptose nas várias zonas da adrenal e os resultados das percentagens estão expressos na Tabela 1. Com relação à zona glomerulosa, não foram encontradas diferenças significativas entre os quatro grupos estudados. Já a zona fasciculada mostrou diminuição significativa na percentagem de apoptoses no GExpV (15,5士3,1*; $\mathrm{p}<0,05)$ em relação aos outros grupos (GCont $=21,2 \pm 2,1$;

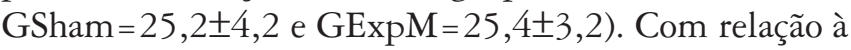
zona reticulada, foi verificado o mesmo padrão observado na zona fasciculada, ou seja, menor percentagem de apoptose no GExpV $\left(8,11 \pm 1,90^{*}, \mathrm{p}<0,05\right)$ em relação aos outros grupos (GCont =12,2 $\pm 2,2 ;$ GSham $=13,4 \pm 1,1$ e $\mathrm{GExpM}=9,5 \pm 2,1)$.

Com relação aos dados do VEGF-A (atividade celular), observou-se reatividade em todas as zonas da adrenal (Figuras 3 e 4), sendo mais intensa nas células presentes da zona glomerulosa em todos os animais dos grupos estudados e menos intensa nas demais zonas. Observando a Tabela 2 , nota-se maior reatividade ao

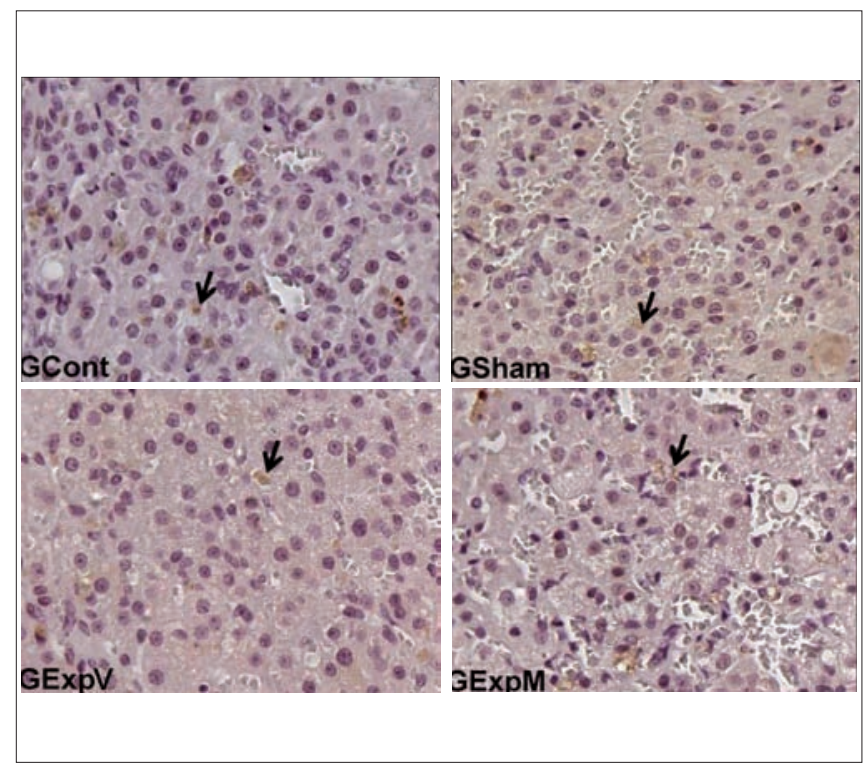

Figura 2 - Fotomicrografias da zona reticulada da região cortical das adrenais de ratas pertencentes aos vários grupos de estudo. Notar no citoplasma de algumas células áreas com coloração marrom indicando reatividade à caspase (setas). Grupo Controle (GCont), Grupo Sham (GSham), Grupo pinealectomizado tratado com veículo (GExpV) e Grupo pinealectomizado tratado com melatonina (GExpM). Imunoistoquímica para a caspase-3-clivada. 400X. 


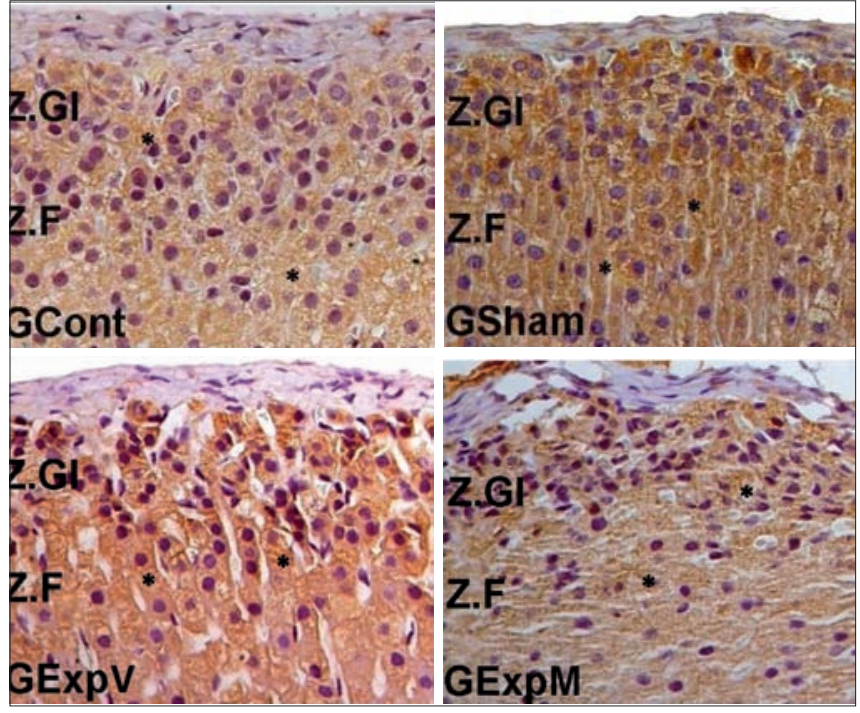

Figura 3 - Fotomicrografias das zonas glomerulosa (Z.Gl) e fasciculada (Z.F) da região cortical das adrenais de ratas pertencentes aos vários grupos de estudo. Notar no citoplasma áreas com coloração marrom indicando reatividade ao VEGF-A (*). Grupo Controle (GCont), Grupo Sham (GSham), Grupo pinealectomizado tratado com veículo (GExpV) e Grupo pinealectomizado tratado com melatonina (GExpM). Imunoistoquímica para o VEGF-A. 400X.

Tabela 1 - Médias e desvio padrão (\%) da reatividade das células presentes nas três zonas da região cortical da adrenal, à caspase-3-clivada, de ratas pinealectomizadas e tratadas com melatonina

\begin{tabular}{lcccc}
\hline \multirow{3}{*}{ Zonas } & \multicolumn{4}{c}{ Grupos } \\
\cline { 2 - 5 } & $\begin{array}{c}\text { GCont } \\
(\mathrm{n}=10)\end{array}$ & $\begin{array}{c}\text { GSham } \\
(\mathrm{n}=10)\end{array}$ & $\begin{array}{c}\text { GExpV } \\
(\mathrm{n}=10)\end{array}$ & $\begin{array}{c}\text { GExpM } \\
(\mathrm{n}=10)\end{array}$ \\
\hline Glomerulosa & $20,1 \pm 2,1$ & $19,5 \pm 3,3$ & $21,1 \pm 2,1$ & $19,4 \pm 3,1$ \\
Fasciculada & $21,2 \pm 2,1$ & $25,2 \pm 4,2$ & $15,5 \pm 3,1^{\star}$ & $25,4 \pm 3,2$ \\
Reticulada & $12,2 \pm 2,2$ & $13,4 \pm 1,1$ & $08,1 \pm 1,9^{\star}$ & $09,5 \pm 2,1$ \\
\hline
\end{tabular}

GCont: Grupo Controle; GSham: falsamente pinealectomizado; GExpV: pinealectomizado tratado com veículo; GExpM: pinealectomizado tratado com melatonina; n: número de animais. ${ }^{*} \mathrm{p}<0,05$.

VEGF-A nas células presentes na zona fasciculada no grupo pinealectomizado tratado com veículo (GExpV) em relação aos demais.

\section{Discussão}

A finalidade deste estudo foi verificar a influência da melatonina sobre a apoptose e a atividade celular (VEGF-A) nas camadas do córtex da adrenal, pois existem relatos de que a melatonina interfere na função da suprerrenal humana, atenuando a produção do cortisol dependente do $\mathrm{ACTH}^{16}$. Estudos anteriores mostraram que ratas submetidas à pinealectomia têm disfunção endócrina e reprodutiva com inúmeros cistos ovarianos, redução no número de oócitos e elevação nos níveis séricos de androgênios, o que mimetiza a anovulação crônica em mulheres ${ }^{8,14,15}$. Além disso, Soares Junior et al. ${ }^{17}$ mostraram que ratas pinealectomizadas tinham maior ingestão

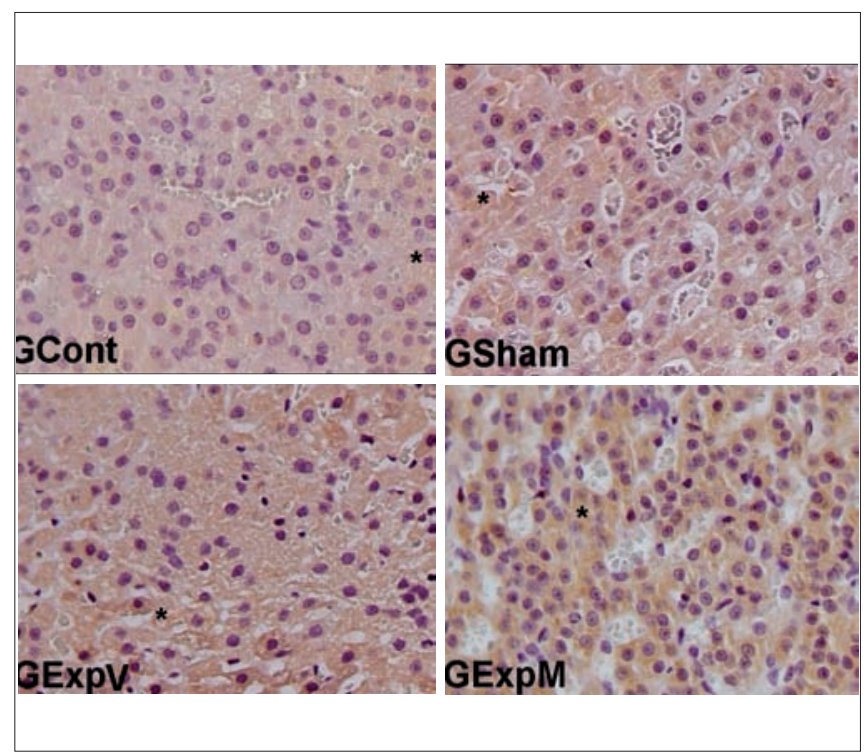

Figura 4 - Fotomicrografias da zona reticulada da região cortical das adrenais de ratas pertencentes aos vários grupos de estudo. Notar no citoplasma áreas de coloração marrom (asterisco) indicando reatividade ao VEGF-A. Grupo Controle (GCont), Grupo Sham (GSham), Grupo pinealectomizado tratado com veículo (GExpV) e Grupo pinealectomizado tratado com melatonina (GExpM). Imunoistoquímica para o VEGF-A. 400X.

Tabela 2 - Reatividade (em escore) das células presentes nas três zonas da região cortical da adrenal, ao fator de crescimento endotelial vascular (VEGF-A) em ratas pinealectomizadas e tratadas com melatonina

\begin{tabular}{lcccc}
\hline \multirow{3}{*}{ Zonas } & \multicolumn{4}{c}{ Grupos } \\
\cline { 2 - 5 } & $\begin{array}{c}\text { GCont } \\
(n=10)\end{array}$ & $\begin{array}{c}\text { GSham } \\
(n=10)\end{array}$ & $\begin{array}{c}\text { GExpV } \\
(n=10)\end{array}$ & $\begin{array}{c}\text { GExpM } \\
(n=10)\end{array}$ \\
\hline Glomerulosa & ++ & ++ & ++ & ++ \\
Fasciculada & + & + & ++ & + \\
Reticulada & + & + & + & + \\
\hline
\end{tabular}

+ a +++ representam graus de reatividade de cor (escore) ao fator de crescimento endotelial vascular. GCont: grupo controle; GSham: falsamente pinealectomizado; GExpV: pinealectomizado tratado com veículo; GExpM: pinealectomizado tratado com melatonina; $n$ : número de animais.

de solução salina e sugeriram que a adrenal poderia estar envolvida.

Deve-se salientar que investigadores sugerem que haveria também alteração na função da suprerrenal em mulheres com a síndrome dos ovários policísticos ${ }^{18}$. Por esta razão, decidimos avaliar todas as camadas do córtex das adrenais de ratas adultas para avaliar as alterações histomorfológicas, bem como a apoptose e proliferação (angiogênese) nessas estruturas. Nossos resultados sugerem remodelação contínua das células nas diversas zonas da adrenal, pois há reatividade à caspase-3-clivada em todos os grupos estudados, ou seja, as células continuam entrando em apoptose.

A apoptose é um processo controlado geneticamente e complexo para o desenvolvimento e homeostase, além de alguns processos patológicos, sendo ativada em resposta a sinais ambientais (fatores extrínsecos) ou desencadeada por fatores intrínsecos, para eliminar células de maneira ordenada na ausência de processo inflamatório. A apoptose está 
intimamente ligada à ação de proteases, denominadas caspases. Dentre estas, a caspase- 3 tem sido largamente usada como marcador imunoistoquímico por representar a confluência entre os mecanismos intrínsecos e extrínsecos da apoptose, e, uma vez ativada, seu processo se torna irreversível ${ }^{19}$.

Esses resultados mostram uma redução na percentagem de apoptose nas zonas reticulada e fasciculada no grupo submetido à pinealectomia (GExpV), ou seja, baixos níveis de melatonina. Já a reposição desse hormônio nos animais pinealectomizados (GExpM) normalizou os níveis apoptóticos das duas zonas. Tal redução na percentagem de apoptose pode ser a principal razão de o tamanho da adrenal macroscopicamente ser maior no GExpV do que nos demais grupos. Na zona glomerulosa, não foram observadas alterações significantes em relação ao percentual de apoptose, em nenhum dos grupos estudados. Tal fato pode ter ocorrido em razão de esta zona estar basicamente relacionada à produção de mineralocorticoides que regulam os níveis séricos dos minerais presentes no plasma sanguíneo ${ }^{20}$.

A zona reticulada apresentou o menor índice apoptótico no grupo em que as ratas foram pinealectomizadas (GExpV), havendo diferença significante em relação aos animais tratados com melatonina (GExpM). Esse achado entra em conflito com os encontrados em trabalho anterior ${ }^{21}$, que observou, por meio do método TUNEL, que só a zona reticulada teve reação imunopositiva. Os mesmos autores relatam também que, nos animais com seis meses de pós-operatório, o número de células em apoptose foi maior que nos outros grupos ${ }^{21}$. Isso confirma outro estudo, no qual se estudou a apoptose na região cortical da adrenal de ratas hipofisectomizadas, observando-se células em apoptose exclusivamente na zona reticulada, o que sugere que o hormônio adrenocorticotrófico (ACTH) seria o único hormônio pituitário capaz de bloquear a apoptose nas células da região cortical ${ }^{22}$.
O fator de crescimento vascular endotelial (VEGF) é um potente e seletivo fator mitogênico para o endotélio. Ele produz resposta angiogênica rápida e aumento da permeabilidade capilar, o que leva a aumento na atividade celular, sendo precoce em relação à síntese do DNA durante a proliferação celular ${ }^{23}$. Pertence à família das glicoproteínas, que inclui o VEGF-A, VEGF-B, VEGF-C, VEGF-D e o fator de crescimento placentário, sendo secretado por inúmeras células ${ }^{24}$. O VEGF-A é o marcador para vasos recentes, por isso a sua utilização. Observamos maior marcação do VEGF-A no grupo pinealectomizado tratado com veículo (GExpV) em relação aos demais grupos. Estes dados apoiam os resultados obtidos na percentagem de apoptose, ou seja, as adrenais neste grupo de animais apresentam maior atividade celular, pois há maior concentração de vasos recém-formados e menor taxa de morte celular, fato este corroborado pelo maior volume das adrenais. No tecido ovariano, constatamos aumento da expressão deste fator nos folículos ovarianos de ratas pinealectomizadas ${ }^{14}$.

Finalmente, é possível sugerir que a melatonina teria influência sobre a cortical da adrenal em ratas pinealectomizadas, em especial nas zonas fasciculada e reticulada.

\section{Agradecimentos}

Aos integrantes do Departamento de Ginecologia e do Departamento de Morfologia e Genética da UNIFESP e à Coordenação de Aperfeiçoamento de Pessoal de Nível Superior (CAPES).

Este trabalho teve como agência financiadora o Conselho Nacional de Desenvolvimento Científico e Tecnológico (CNPq) e a Coordenação de Aperfeiçoamento de Pessoal de Nível Superior (CAPES).

\section{Referências}

1. Hu J, Zhang Z, Shen WJ, Azhar S. Cellular cholesterol delivery, intracellular processing and utilization for biosynthesis of steroid hormones. Nutr Metab (Lond). 2010;7:47.

2. Miller WL. Androgen biosynthesis from cholesterol to DHEA. Mol Cell Endocrinol. 2002;198(1-2):7-14.

3. Jung CM, Khalsa SB, Scheer FA, Cajochen C, Lockley SW, Czeisler $\mathrm{CA}$, et al. Acute effects of bright light exposure on cortisol levels. J Biol Rhythms. 2010;25(3):208-16.

4. Cecon E, Fernandes PA, Pinato L, Ferreira ZS, Markus RP. Daily variation of constitutively activated nuclear factor kappa B (NFKB) in rat pineal gland. Chronobiol Int. 2010;27(1):52-67.

5. Kachi T, Tanaka D, Watanabe S, Suzuki R, Tonosaki Y, Fujieda $\mathrm{H}$. Physiological pineal effects on female reproductive function of laboratory rats: prenatal development of pups, litter size and estrous cycle in middle age. Chronobiol Int. 2006; 23(1-2):289-300.
6. Falcón J, Besseau L, Fuentès M, Sauzet S, Magnanou E, Boeuf G. Structural and functional evolution of the pineal melatonin system in vertebrates. Ann N Y Acad Sci. 2009;1 163:101-11.

7. Sumaya IC, Masana MI, Dubocovich ML. The antidepressant-like effect of the melatonin receptor ligand luzindole in mice during forced swimming requires expression of MT2 but not MT1 melatonin receptors. J Pineal Res. 2005;39(2):170-7.

8. Maganhin CC, Carbonel AA, Hatty JH, Fuchs LF, Oliveira-Júnior IS, Simões $M$, et al. Melatonin effects on the female genital system: a brief review. Rev Assoc Med Bras. 2008;54(3):267-71.

9. Johnson LY, Vaughan MK, Richardson BA, Petterborg L, Reiter RJ. Variation in pineal melatonin content during the estrous cycle of the rat. Proc Soc Exp Biol Med. 1982;169(3):416-9.

10. Gittes RF, Chu EW. Reversal of the effect of pinealectomy in female rats by multiple isogeneic pineal transplants. Endocrinology. $1965 ; 77(6): 1061-7$. 
11. Lima LMB, Lima MA, Rita CVC, Oliveira PF, Reis LC, Borges $M F$, et al. Influência da pineal sobre a morfologia do córtex da adrenal. Medicina (Ribeirão Preto). 2002;35(1):36-40.

12. Olfert ED, Cross BM, McWilliam AA, editors. Canadian Council on Animal Care's guide to the care and use of experimental animals. 2nd ed. Ottawa: Bradda Printing Services; 1993.

13. Dair EL, Simoes RS, Simões M, Romeu LR, Oliveira-Filho RM, Haidar $M A$, et al. Effects of melatonin on the endometrial morphology and embryo implantation in rats. Fertil Steril. 2008;89(5):1299-305.

14. Romeu LR, da Motta EL, Maganhin CC, Oshima CT, Fonseca $M C$, Barrueco KF, et al. Effects of melatonin on histomorphology and on the expression of steroid receptors, VEGF, and PCNA in ovaries of pinealectomized female rats. Fertil Steril. In press 2010.

15. Maganhin CC, Simões RS, Fuchs LFP, Oliveira-Filho RM, Simões M, Evêncio Neto J, et al. Rat pinealectomy: a modified direct visual approach. Acta Cir Bras. 2009;24(4):321-4.

16. Campino C, Valenzuela F, Arteaga E, Torres-Farfán C, Trucco C, Velasco $A$, et al. La melatonina reduce la respuesta de cortisol al ACTH en humanos. Rev Med Chil. 2008;136(11):1390-7.

17. Soares Junior JM, Baracat EC, Oliveira S, Haidar MA, Simões M, Reis LC. Influência da glândula pineal sobre a ingestão de água e $\mathrm{NaCl}$ em ratas normais e ooforectomizadas. Rev Bras Ginecol Obstet. 1999;21(6):317-21.
18. Roelfsema F, Kok $\mathrm{P}$, Pereira $\mathrm{AM}, \mathrm{Pijl} \mathrm{H}$. Cortisol production rate is similarly elevated in obese women with or without the polycystic ovary syndrome. J Clin Endocrinol Metab. 2010;95(7): 3318-24.

19. Orimoto AM, Dumaresq-Doiron K, Jiang JY, Tanphaichitr N, Tsang BK, Carmona E. Mammalian hyaluronidase induces ovarian granulosa cell apoptosis and is involved in follicular atresia. Endocrinology. 2008; 149(1 1):5835-47.

20. Rom-Bugoslavskaia ES, Komarova IV, Bondarenko LA. Seasonal dynamics of adrenal mineralocorticoid function in rats. Biull Eksp Biol Med. 1988; 105(2):221-4.

21. Evêncio-Neto J, Baratella-Evêncio L, Teixeira AAC, Teixeira VW, Simões M. Programmed cell death and cellular proliferation in the adrenal glands of the pinealectomized rats. Acta Microsc. 2001;10(2):75-6.

22. Carsia RV, Macdonald GJ, Gibney JA, Tilly KI, Tilly JL. Apoptotic cell death in the rat adrenal gland: an in vivo and in vitro investigation. Cell Tissue Res. 1996;283(2):247-54.

23. García MN, Andrini LB, Inda AM, Ronderos JR, Hijano JC, Errecalde AL. Changes in VEGF expression and DNA synthesis in hepatocytes from hepatectomized and tumour-bearing mice. Cell Biol Int. 2010;34(3):283-6.

24. Stuttfeld E, Ballmer-Hofer K. Structure and function of VEGF receptors. IUBMB Life. 2009;61(9):915-22. 